\title{
Effects of Tourniquet in Total Knee Arthroplasty
}

\author{
Serkan Akpancar1', Oner Tatar'2, Hasan Turgut ${ }^{3}$, Safak Ekinci ${ }^{4}$ \\ ${ }^{1}$ Department of Orthopaedic Surgery, Gulhane Military Hospital, Ankara, Turkey \\ ${ }^{2}$ Department of Orthopaedic Surgery, Kasımpasa Military Hospital, Istanbul, Turkey \\ ${ }^{3}$ Department of Orthopedic Surgery, Bursa Military Hospital, Bursa, Turkey \\ ${ }^{4}$ Department of Orthopaedic Surgery, Haydarpasa Gulhane Military Hospital, Istanbul, Turkey \\ Email: safakekinci@yahoo.com
}

Received 14 February 2016; accepted 9 April 2016; published 12 April 2016

Copyright (C) 2016 by authors and Scientific Research Publishing Inc.

This work is licensed under the Creative Commons Attribution International License (CC BY). http://creativecommons.org/licenses/by/4.0/

(c) (i) Open Access

\section{Abstract}

Tourniquet has long been used in TKA (Total Knee Arthroplasty) as the other orthopedic procedures for decreasing operation time and blood loss, providing better visualization of anatomic structures. While having much more advantages, these devices have a potential of serious complications, so they must be used with adequate knowledge and attention. Paralysis, compression neuropathy, compartment syndrome, prolonged period of rehabilitation, edema, pain, skin problems, nerve damage and systemic problems are the some complications seen. Selections of appropriate blood pressure, cuff selection, tourniquet timing are the essential points of tourniquet use. Through these increasing complication rates and improvements in the surgical and anesthesia methods contrary to old beliefs, surgery has been preferred without tourniquet in the patients who have no cardio-vascular problems and morbidity. In the patients who have any contraindicated situations as stated above, TKA must be performed with tourniquet, with proper control of the amount of pressure and the duration of application, the risk of complications decrease, in the other situations TKA can be performed without tourniquet with the aims for fast-recovery, postsurgical pain relief and better muscle activity. The objective of this paper is to describe current perspectives of tourniquet use in total knee arthroplasty.

\section{Keywords}

Tourniquet, Total Knee Arthroplasty

\section{Introduction}

Jean Lous Petit firstly introduced tourniquet to surgery in 1718 [1]. Intra and Post-operative mean blood loss 
about 1000 - 1500 cc, transfusion requirement of much more patients, ABO incompatibility and infections due to immunosuppression have made mandatory these instruments in the extremity surgeries. Providing better visualization of anatomic structures, facilitation of sementing and other surgical procedures, decreasing the blood loss in the operation are the advantages of tourniquets [2] [3].

Total knee arthroplasty (TKA) is one of the major orthopedic operations and tourniquet has long been used for decreasing operation time, blood loss, inflammation and muscle-tissue damage in this procedure [2] [3]. While having much more advantages, these devices have a potential of serious complications in the patients of total knee arthroplasty, so they must be used with adequate knowledge and attention. Paralysis, compression neuropathy, compartment syndrome, prolonged period of rehabilitation, edema, pain, skin problems, nerve damage and systemic problems are the some complications seen in TKA as in the other major orthopedic procedures [4].

The objective of this paper is to describe current perspectives of tourniquet use in total knee arthroplasty.

\section{Essential Points of Tourniquet Use}

\subsection{Selecting of Appropriate Blood Pressure}

Most preferred pressure for upper extremity is $200 \mathrm{mmHg}$ and $250 \mathrm{mmHg}$ for lower extremity. Olivecrona et al. reported that the risk of perioperative complications increased when the mean cuff pressure was more than 293 $\mathrm{mm} \mathrm{Hg} \mathrm{[5].} \mathrm{Previous} \mathrm{studies} \mathrm{have} \mathrm{shown} \mathrm{that} \mathrm{with} \mathrm{the} \mathrm{higher} \mathrm{amounts} \mathrm{of} \mathrm{tourniquet} \mathrm{pressure} \mathrm{and} \mathrm{prolonged}$ tourniquet time, the risk of postoperative complications such as DVT, wound complications, and deep infection increased [4] [6] [7]. When the appropriate blood pressure determining, arterial occlusion pressure is taken into account instead of systolic blood pressure. It is measured with stethoscope, doppler flowmetry and pulse oximeter, and is the lowest pressure that prevents the circulation. Optimal Tourniquet pressure must be in these intervals Arterial occlusion pressure + safety interval [8].

- $\mathrm{AOB}+40 \mathrm{mmHg}(\mathrm{AOB}<130 \mathrm{mmHg})$.

- $\mathrm{AOB}+60 \mathrm{mmHg}(\mathrm{AOB} 131-190 \mathrm{mmHg})$.

- $\mathrm{AOB}+80 \mathrm{mmHg}(\mathrm{AOB}>190 \mathrm{mmHg})$.

\subsection{Cuff Selection}

Appropriate tourniquet length must be half of the extremity diameter. It must be implemented most proximal circular area to the incision. Due to the effective bleeding control with lower pressure, the wider tourniquet must be used from extremity proximal to incision. 2 fingers can be able to enter both of the distal and proximal of the cuff. Cuff ends must overlap 7 - 15 centimeters not to be longer or shorter. When the diameters of the extremity proximal and distal diameters are equal cylindrical tourniquet; if the proximal diameter is thicker than distal cone, tourniquet must be chosen [9].

\subsection{Tourniquet Timing}

Tourniquet timing is an essential part of the major orthopedic operations and it is known to be performed short as much as possible, not excess for 120 minutes, if it is to be excess deflate and inflate again [6]. The prolonged duration of tourniquet used is thought to be the crucial factor for complications, which induced longer ischemic time for tissues. Harvey et al. [10] reported that prolonged tourniquet application is associated with more bleeding after deflation because of increased fibrinolytic activity. Sherman et al. [11] stated that there is a moderate risk of complications when tourniquet is performed between 40 and 60 minutes, there is a high risk when performed above 60 minutes in his study of 2640 arthroscopic procedures. Jorgensen [12] reported that performing the tourniquet application under the duration of 150 minutes, significantly reduces the risk of complications. Wound oozing and nerve injury are the significant complications reported with prolonged duration of tourniquet [13]-[15].

For the aim of reducing the prolonged tourniquet time some investigators advised tourniquet release before wound closure and declared that tourniquet release after wound closure could cause more excessive inflammation and muscle damage, minimizing blood loss and contribute to less discomfort postoperatively and earlier functional recovery [16]-[18]. Tourniquet release before wound closure for hemostasis reduced the risks of overall complications and major complications. Every prolonged application of $10 \mathrm{~min}$ of time was associated with an increased risk for complications [19]. Some studies stated that better subjective performance and earlier 
functional recovery were observed at early postoperative follow-up with early tourniquet release [17] [20]. However, other investigators have reported conflicting results [21] [22]. Zeyu Huang [23] stated that tourniquet release after wound closure for hemostasis could significantly decrease the total measured blood loss in patients treated with TKA. Wei Zhang et al. [24] compared outcomes RCT studies of tourniquet release before wound closure for hemostasis with tourniquet release after wound closure and stated there were no significant differences in the hemoglobin drop, overt blood loss, rate of transfusion, and volume of transfusion between tourniquet release before wound closure for hemostasis and tourniquet release after wound closure in TKA. Widman et al. found no difference in the range of motion between the early and late release group at the first postoperative follow-up 2 - 3 months after TKA [25].

\section{General Complications of Tourniquet}

There are a number of complications, both local and systemic. However, rates of complications are rare. Some of them can be devastating, and may cause permanent loss of function, or damage to the limb. Complications are commonly due to mechanical compression of the structures due to ischemia, and reperfusion effects.

\subsection{Local Complications}

- Muscle-tissue ischemia.

- Paralysis, compression neuropathy.

- Compartment syndrome.

- Prolonged period of rehabilitation.

- Edema, pain.

- Skin problems.

- Nerve damage.

\subsection{Systemic Complications}

- Deep venous thrombosis, pulmonary embolism.

- Hyperkalemia, acidosis.

- Increasing in circulating blood volume.

- The possibility of cardiac decompensation.

- Central venous pressure-increase in systemic blood pressure.

- Tachycardia.

- Body temperature increasing.

\subsection{Most Accused Reasons}

- Long-term use.

- High pressure.

- Each patient in the same tourniquet.

- Inappropriate sleeve.

- Inability to protect skin.

\section{Total Knee Arthroplasty without Tourniquet}

Through these increasing complication rates and improvements in the surgical and anesthesia methods contrary to old beliefs, surgery has been preferred without tourniquet in the patients who have no cardio-vascular problems and morbidity. Thus fast-recovery and post-surgical pain relief is provided without tourniquet [17] [19]. Additionally due to the lack of local pressure or rhabdomyolysis; rapid return of knee flexion in the early postoperative period is provided [26]. H. M. Wakankar et al. [3] mentioned that patients without tourniquet have a faster recovery and better flexion gap in the early period (1 week); however, wound complications, deep vein trombosis rates, pain control and range of motion in the 6 months of post-operative period is same between the tourniquet and non-tourniquet use. Nishikant Kumar et al. [27] evaluated pain in the patients with the comparison of non-turniquet and tourniquet use in TKA with a prospective randomized control trial and declined nontourniquet use in TKA provides less early postoperative pain and better recovery. Dennis et al. [28] stated that in 
the patients who underwent TKA with tourniquet, quadriceps strength had diminished during the first 3 months after TKA. Hamstring strength did not differ between groups at any time point. David Liu et al. [29] evaluated effects of tourniquet use on Quadriceps Function and Pain in Total Knee Arthroplasty in a prospective randomized single-blinded study and found a significant difference in pain scores on 2 and 4 days. However there was no difference in Oxford knee scores, range of motion, or thigh and knee swelling up to 12 months of post-operative duration. Three patients in the tourniquet group required a blood transfusion whereas none in the non-tourniquet group did $(\mathrm{p}=0.05)$. The tourniquet group showed significantly less muscle activity as measured by surface EMG than the non-tourniquet group; however, the energy output was similar between the two groups at 6 months of post-operative duration. Quadriceps functions returned to equivalent with the non-operative leg both of the tourniquet and no tourniquet group at post-operative 12 months.

Ta-Wei Tai [2] stated that the use of a tourniquet during TKA is effective for reducing blood loss and decreasing excessive postoperative inflammation and muscle damage. Patients have slightly less pain without tourniquet. They found no significant differences between tourniquet and non-tourniquet in terms of swelling, rehabilitation progress, or hospital stays.

Some agents have used for decreasing blood loss in the patients with no-usage of tourniquet lately.

Aprotin: It is serine protease analog that obtained from bovine lung and inhibits the final stage of fibrinolysis. However it has complications as allergy, thrombosis, nephrotoxicity and Spongiform encephalopathy.

Aminokaproik Acid: Acts for inhibition of plasminogen activation and decreases the risk of thrombus, thromboembolic complications and transfusion requirements.

Tranexamic Acid: It is a synthetic analogue of serin that inhibits fibrinolysis with inhibiting the lysine-attached regions of plasmin and plasminogen activator molecules. It has been used for cardiovascular surgery, urology, and gynecology for 20 years. It is effect starts after 10 - 15 minutes of infusion. The starting dose is 15 $\mathrm{mg} / \mathrm{kg}$ and recommended two doses instead of single. It provides significant reduction in post-op bleeding, reduced risk of allogenic blood transfusion and tourniquet complications [1]. Peng-Fei Shen et al. [30] evaluated effectiveness and safety of tranexamic acid for TKA in a prospective randomized controlled trial found significant difference in post-operative12-h drainage, post-operative 24-h D-dimer values, total drainage volume, hidden blood loss, total blood loss, and the rate of postoperative ecchymosis.

\section{Conclusion}

Tourniquet in TKA has much more advantages, however it is a potential of serious complications, so they must be used with adequate knowledge and attention. In the patients who have cardio-vascular problems, morbidity or any contraindicated situations, TDP must be performed with tourniquet. With proper control of the amount of pressure and the duration of application, the risk of complications decreases. In the patients have no problems as stated above, TDP can be performed without tourniquet with the aims for fast-recovery, post-surgical pain relief and better muscle activity. Some studies offer tourniquet release before wound closure for hemostasis or better post-operative functions however some studies state just the opposite so there is not enough evidence about the tourniquet release before or after wound closure.

\section{References}

[1] Ortega-Andreu, M., Pérez-Chrzanowska, H., Figueredo, R. and Gómez-Barrena, E. (2011) Blood Loss Control with Two Doses of Tranexamic Acid in a Multimodal Protocol for Total Knee Arthroplasty. The Open Orthopaedics Journal, 5, 44-48.

[2] Tai, T.W., Chang, C.W., Lai, K.A, Lin, J. and Yang, C.Y. (2012) Effects of Tourniquet Use on Blood Loss and SoftTissue Damage in Total Knee Arthroplasty: A Randomized Controlled Trial. The Journal of Bone and Joint Surgery, American Volume, 94, 2209-2215.

[3] Wakankar, H.M., Nicholl, J.E., Koka, R. and D’Arcy, J.C. (1999) The Tourniquet in Total Knee Arthroplasty. Journal of Bone and Joint Surgery (British Volume), 81-B, 30-33.

[4] Aglietti, P., Baldini, A., Vena, L.M., Abbate, R., Fedi, S. and Falciani, M. (2000) Effect of Tourniquet Use on Activation of Coagu-Lation in Total Knee Replacement. Clinical Orthopaedics and Related Research, 371, 169-177. http://dx.doi.org/10.1097/00003086-200002000-00021

[5] Olivecrona, C., Blomfeldt, R., Ponzer, S., Stanford, B.R. and Nilsson, B.Y. (2013) Tourniquet Cuff Pressure and Nerve İnjury in Knee Arthroplasty in a Bloodless Field: A Nneurophysiological Study. Acta Orthopaedica, 84, 159-164. http://dx.doi.org/10.3109/17453674.2013.782525 
[6] Horlocker, T.T., Hebl, J.R., Gali, B., et al. (2006) Anesthetic, Patient, and Surgical Risk Factors for Neurologic Complications after Prolonged Total Tourniquet Time during Total Knee Arthroplasty. Anesthesia \& Analgesia, 102, 950-955. http://dx.doi.org/10.1213/01.ane.0000194875.05587.7e

[7] Olivecrona, C., Ponzer, S., Hamberg, P. and Blomfeldt, R. (2012) Lower Tourniquet Cuff Pressure Reduces Postoperative Wound Complications after Total Knee Arthroplasty: A Randomized Controlled Study of 164 Patients. The Journal of Bone and Joint Surgery, American Volume, 94, 2216-2221. http://dx.doi.org/10.2106/JBJS.K.01492

[8] Noordin, S., McEwen, J.A., Kragh Jr., C.J.F., Eisen, A. and Masri, B.A. (2010) Surgical Tourniquets in Orthopaedics. The Journal of Bone and Joint Surgery, American Volume, 91, 2958-2967.

[9] Murphy, C.G., Winter, D.C. and Bouchier-Hayes, D.J. (2005) Tourniquet Injuries: Pathogenesis and Modalities for Attenuation. Acta Orthopeedica Belgica, 71, 635-645.

[10] Harvey, E.J., Leclerc, J., Brooks, C.E. and Burke, D.L. (1997) Effect of Tourniquet Use on Blood Loss and İncidence of Deep Vein Thrombosis in Total Knee Arthroplasty. The Journal of Arthroplasty, 12, 291-296. http://dx.doi.org/10.1016/S0883-5403(97)90025-5

[11] Sherman, O.H., Fox, J.M., Snyder, S.J., et al. (1986) Arthroscopy-“No-Problem Surgery”: An Analysis of Complications in Two Thousand Six Hundred and Forty Cases. The Journal of Bone and Joint Surgery (American Volume), 68, 256-265.

[12] Jorgensen, H.R. (1987) Myoglobin Release after Tourniquet Ischemia. Acta Orthopaedica Scandinavica, 58, 554-556. http://dx.doi.org/10.3109/17453678709146398

[13] Butt, U., Ahmad, R., Aspros, D. and Bannister, G.C. (2011) Factors Affecting Wound Ooze in Total Knee Replacement. Annals of The Royal College of Surgeons of England, 93, 54-56. http://dx.doi.org/10.1308/003588410X12771863937124

[14] Jacob, A.K., Mantilla, C.B., Sviggum, H.P., Schroeder, D.R., Pagnano, M.W. and Hebl, J.R. (2011) Perioperative Nerve Injury after Total Knee Arthroplasty: Regional Anesthesia Risk during a 20-Year Cohort Study. Anesthesiology, 114, 311-317. http://dx.doi.org/10.1097/ALN.0b013e3182039f5d

[15] Tai, T.W., Lin, C.J., Jou, I.M., Chang, C.W., Lai, K.A. and Yang, C.Y. (2011) Tourniquet Use in Totalknee Arthroplasty: A Meta-Analysis. Knee Surgery, Sports Traumatology, Arthroscopy, 19, 1121-1130. http://dx.doi.org/10.1007/s00167-010-1342-7

[16] Huang, Z.Y., Pei, F.X., Ma, J., Yang, J., Zhou, Z.K., De Kang, P. and Shen, B. (2014) Comparison of Three Different Tourniquet Application Strategies for Minimally Invasive Total Knee Arthroplasty: A Prospective Non-Randomized Clinical Trial. Archives of Orthopaedic and Trauma Surgery, 134, 561-570. http://dx.doi.org/10.1007/s00402-014-1948-1

[17] Barwell, J., Anderson, G., Hassan, A. and Rawlings, I. (1997) The Effects of Early Tourniquet Release during Total Knee Arthro-Plasty: A Prospective Randomized Double-Blind Study. The Journal of Bone and Joint Surgery (British Volume), 79, 265-268. http://dx.doi.org/10.1302/0301-620X.79B2.7191

[18] Chang, C.W., Lan, S.M., Tai, T.W., Lai, K.A. and Yang, C.Y. (2012) An Effective Method to Reduce Ischemia Time during Total Knee Arthroplasty. Journal of the Formosan Medical Association, 111, 19-23. http://dx.doi.org/10.1016/j.jfma.2012.01.006

[19] Olivecrona, C., Lapidus, L.J., Benson, L. and Blomfeldt, R. (2013) Tourniquet Time Affects Postoperative Complications after Knee Arthroplasty. International Orthopaedics, 37, 827-832. http://dx.doi.org/10.1007/s00264-013-1826-4

[20] Kvederas, G., Porvaneckas, N., Andrijauskas, A., Svensen, C.H., Ivaskevicius, J., Mazunaitis, J., Marmaite, U., Marmaite, U. and Andrijauskas, P. (2013) A Randoized Double-Blind Clinical Trial of Tourniquet Application StrateGies for Total Knee Arthroplasty. Knee Surgery, Sports Traumatology, Arthroscopy, 21, 2790-2799. http://dx.doi.org/10.1007/s00167-012-2221-1

[21] Newman, J.H., Jackson, J.P. and Waugh, W. (1979) Timing of Tourniquet Removal after Knee Replacement. Journal of the Royal Society of Medicine, 72, 492-494.

[22] Lotke, P.A., Faralli, V.J., Orenstein, E.M. and Ecker, M.L. (1991) Blood Loss after Total Knee Replacement: Effects of Tourniquet Release and Continuous Passive Motion. The Journal of Bone and Joint Surgery (American Volume), 73, 1037-1040.

[23] Huang, Z., Ma, J., Zhu, Y., Pei, F., Yang, J., Zhou, Z. and Shen, B. (2015) Timing of Tourniquet Release in Total Knee Arthroplasty. Orthopedics, 38, 445-451. http://dx.doi.org/10.3928/01477447-20150701-06

[24] Zhang, W., Liu, A., Hu, D., Tan, Y., Al-Aidaros, M. and Pan, Z. (2014) Effects of the Timing of Tourniquet Release in Cemented Total Knee Arthroplasty: A Systematic Review and Meta-Analysis of Randomized Controlled Trials. Journal of Orthopaedic Surgery and Research, 9, 125.

[25] Widman, J. and Isacson, J. (1999) Surgical Hemostasis after Tourniquet Release Does Not Reduce Blood Loss in Knee 
Replacement. A Prospective Randomized Study of 81 Patients. Acta Orthopaedica Scandinavica, 70, 268-270. http://dx.doi.org/10.3109/17453679908997805

[26] Vandenbussche, E., Duranthon, L.-D., Couturier, M., Pidhorz, L. and Augereau, B. (2002) The Effect of Tourniquet Use in Total Knee Arthroplasty. International Orthopaedics, 26, 306-309. http://dx.doi.org/10.1007/s00264-002-0360-6

[27] Kumar, N., Yadav, C., Singh, S., Kumar, A., Vaithlingam, A. and Yadav, S. (2015) Evaluation of Pain in Bilateral Total Knee Replacement with and without Tourniquet; a Prospective Randomized Control Trial. Journal of Clinical Orthopaedics and Trauma, 6, 85-88.

[28] Dennis, D.A., Kittelson, A.J., Yang, C.C., Miner, T.M., Kim, R.H. and Stevens-Lapsley, J.E. (2016) Does Tourniquet Use in TKA Affect Recovery of Lower Extremity Strength and Function? A Randomized Trial. Clinical Orthopaedics and Related Research, 474, 69-77.

[29] Liu, D., Graham, D., Gillies, K. and Gillies, R.M. (2014) Effects of Tourniquet Use on Quadriceps Function and Pain in Total Knee Arthroplasty. Knee Surgery \& Related Research, 26, 207-213. http://dx.doi.org/10.5792/ksrr.2014.26.4.207

[30] Shen, P.F., Hou, W.L., Chen, J.B., Wang, B. and Qu, Y.X. (2015) Effectiveness and Safety of Tranexamic Acid for Total Knee Arthroplasty: A Prospective Randomized Controlled Trial. Medical Science Monitor: International Medical Journal of Experimental and Clinical Research, 21, 576-581. http://dx.doi.org/10.12659/MSM.892768 